\title{
PEA PEEL WASTE: A LIGNOCELLULOSIC WASTE AND ITS UTILITY IN CELLULASE PRODUCTION BY Trichoderma reesei UNDER SOLID STATE CULTIVATION
}

\author{
Nitin Verma,* Mukesh C. Bansal, and Vivek Kumar \\ A wide variety of waste bioresources are available on our planet for \\ conversion into bioproducts. In the biological systems, microorganisms \\ are used to utilize waste as an energy source for the synthesis of \\ valuable products such as biomass proteins and enzymes. The large \\ quantities of byproducts generated during the processing of plant food \\ involve an economic and environmental problem due to their high \\ volumes and elimination costs. After isolation of the main constituent, \\ there are abundant remains which represent an inexpensive material that \\ has been undervalued until now. Pea peel waste is one of the \\ undervalued, unused sources of energy that can serve as a potential \\ source for cellulase production. Batch experiments have been \\ performed, using pea peel waste as a carbon source for cellulase \\ production under solid state cultivation by Trichoderma reesei. It was \\ observed that $30{ }^{\circ} \mathrm{C}$ temperature and $\mathrm{pH} 5.0$ are the most favorable \\ conditions for cellulase production by $T$. reesei. FPase activity \\ significantly increases by incorporation of whey as well as wheat starch \\ hydrolysate in the basal salt media used in the production study. The \\ present study describes the utility of pea peel waste, whey as well as \\ wheat starch hydrolysate in cellulase production by $T$. reesei. The \\ utilization of economically cheap, pea peel waste for cellulase production \\ could be a novel, cost effective, and valuable approach in cellulase \\ production as well as in solid waste management.
}

Key words: Pea peel waste; Whey; Trichoderma reesei; Cellulase; Wheat starch hydrolysate

Contact information: Department of Paper Technology, Indian Institute of Technology, Roorkee, Saharanpur Campus, Saharanpur, 247001, U.P.,(India). *Corresponding Author:nitiniit2008@gmail.com

\section{INTRODUCTION}

Lignocellulosic biomass is the most abundant solid waste in the world; thus it can provide some of the most promising feedstocks for the production of energy, food, and chemicals. Lignocellulose comprises more than 60\% of plant biomass produced by photosynthesis on the Earth. It generally contains up to $75 \%$ of cellulose and hemicelluloses, which are the potential source for the production of glucose and other chemicals. Most microbial cellulases are inducible enzymes, and like other extracellular enzymes, they are secreted when the microorganisms are grown on cellulose or cellulosic components present in the raw materials (Jecu 2000).

Commercial bioconversion of lignocellulosic waste requires the most economical methods of cellulase production. Keeping in view the high demand for cellulases in various process industries, bioconversion processes, and solid waste management, 
effective and economical production of these enzymes is of utmost importance. Therefore, intensive search is being carried out for novel, cheap, and easily available lignocellulosic biomass. Peels form a major portion of whole fruits. At present peels are a waste product, and their disposal has become a great problem. With a view to exploiting pea peel as a source of valuable components, it can be serve as a solid substrate for cellulase production.

Pea peel waste is an outer covering of pea (Pisum sativum $L$ ) vegetable, not the peel of seed. It is cheap and easily available lignocellulosic biomass that can be serve as potential raw material for cellulase production. Pea (Pisum sativum $L$ ) is an annual plant of cool season, belonging to the family leguminosae, and grown in many parts of the world. (Choi and Han, 2001). Pea (Pisum sativum) is the second most important food legume worldwide after common bean (Phaseolus vulgaris L.). It is cultivated on over 5.9 million hectares with a production of about 11.7 million tons annually. In India it is grown on over 0.7 million hectares, yielding about 0.6 million tons. The increasing demand for protein-rich raw materials for animal feed or intermediary products for human nutrition have led to greater interest in this crop as a protein source (Ahmad et al. 2010; Sharma et al. 2006).

Pod of the legumes provides a protective envelop to the developing seeds, acting as a catchment, transport link, and temporary reservoir for solute mobilized from vegetative parts to seeds. The pod wall of pea (Pisum sativum $L$ ) contains two distinct photosynthetic layers. The outer layer, comprising chlorenchyma of the mesocarp, captures $\mathrm{CO}_{2}$ from the outside atmosphere, and the inner chloroplast-containing layer is the epidermis lining (Atkins et al. 1977).

Pulse crops are an excellent source of protein, carbohydrates, as well as fiber and provide many essential vitamins and minerals (Tosh and Yada 2010). Pea cotyledon cell walls are mainly composed of arabinose-rich pectins $(26 \%)$ and hemicelluloses $(22 \%)$, whereas hulls contain primarily cellulose (69\%) (Roy et al. 2010). Sosulski and Wu (1988) also reported that field pea hulls contained $82.3 \%$ (DMB) total dietary fiber with $8.2 \%$ hemicellulose and $62.3 \%$ cellulose. The influence of meteorological conditions such as cultivation years, soil characteristics of the cultivation area, and their nutrient and antinutrient composition strongly affect the composition of pea. Gunaseelara et al. (2007) reported the composition of Pisum sativum $L$ (garden pea) pods without seeds in terms of lignin and cellulose ( $\mathrm{g} / \mathrm{g}$ volatile solid) as 0.087 and 0.174 , respectively.

Peas have the potential to provide high antioxidant compounds other than polysaccharides, proteins, and micronutrients. Generally, phenolics found in fruits and vegetables are bonded to dietary fibers, proteins, or to sugars in plants to form complex structures (Wen et al. 2010). Sultana and Anar (2008) reported the presence of flavanols such as kaempeferol, querecetin and myricetin in the pea seeds. Flavanols are naturally occurring phenolic substances .

On the other hand wheat is among the most important raw materials in the world for obtaining starch and its by-products. Wheat starch grains are bimodal in size: B-starch ( 15 to $20 \%$ ) is 2 to $15 \mu \mathrm{m}$ in diameter, and the larger A-starch granules ( 80 to $85 \%$ ) are 20 to $35 \mu \mathrm{m}$. B-starch is always highly contaminated with pentosans, fine fibres, lipids, and protein (Anon. 2011). Wheat gluten is the water-insoluble protein complex in the wheat endosperm. As suggested in the literature, the water-soluble acid hydrolyzed starch also 
serves as excellent inducer for growth and cellulase production. It induces the enzymes to the same extent as pure cellulose (Chen and Wayman 1993).

The dairy industry is another example of a process industry where a number of effluents are generated, some of which contain nutritionally valuable constituents such as proteins, lactose, fats, etc. One such effluent is whey. Whey is the liquid generated during the manufacture of cheese. Whey samples have a biological oxygen demand in the range of 35,000 to 40,000 mg/L (Marwaha and Kennedy 2007; Anekar and Rao 2009). Due to the higher biochemical oxygen demand $\left(\mathrm{BOD}_{5}\right)$ of whey, it poses a major world-wide disposal and pollution problem; thus an effective and permanent solution is urgently needed (Marwaha and Kennedy 2007; Venkatraman and Achi 2004). The use of soluble carbon sources such as lactose present in the whey for cellulase production allows greater control on fermentation, simplifies the operational process, and induces the cellulase production (Verma et al. 2009).

The present paper describes the utilization of novel, cheap pea peel waste as carbon source for cellulase production along with the utility of dairy industry waste (whey) and wheat starch hydrolysates on its production by Trichoderma reesei.

\section{EXPERIMENTAL}

\section{Materials}

All the chemicals and reagents used to perform the experimental work were of Himedia, Sigma Aldrich, and Merck make. Trichoderma reesei NCIM 1186 was procured from National Chemical Laboratory, Pune. Whey was collected from the local dairy industry, whereas pea peels were collected from local market. Separate sets of batch experiments were carried out in $250 \mathrm{~mL}$ Erlenmeyer flasks containing sieved pea peel waste as the raw material for the growth and production of organisms impregnated with the following production media in $(\mathrm{g} / \mathrm{L})$ urea, $0.3 ;\left(\mathrm{NH}_{4}\right)_{2} \mathrm{SO}_{4}, 1.4 ; \mathrm{KH}_{2} \mathrm{PO}_{4}, 2.0$; $\mathrm{MgSO}_{4} .7 \mathrm{H}_{2} \mathrm{O}$, 0.3; peptone, 1.0; Tween 80, 0.2; $\mathrm{FeSO}_{4} .7 \mathrm{H}_{2} \mathrm{O}, 0.005 ; \mathrm{MnSO}_{4} .7 \mathrm{H}_{2} \mathrm{O}$, $0.0016 ; \mathrm{ZnSO}_{4} .7 \mathrm{H}_{2} \mathrm{O} ; 0.0014 ; \mathrm{CaCl}_{2} .2 \mathrm{H}_{2} \mathrm{O} ; \mathrm{CoCl}_{2} \cdot 6 \mathrm{H}_{2} \mathrm{O}, 0.02$. Pea peel waste bed soaked with basal salt media were autoclaved and then inoculated with specific volume $(0.56 \mathrm{~g} / \mathrm{L}$ cell dry weight) of potato dextrose broth culture solution of Trichoderma reesei. The production flasks were placed in an incubator at $25,27,30,32$, and $35^{\circ} \mathrm{C}$ for 6 days at $\mathrm{pH}$ 5.0. Another set of experiments was performed to study the effect of different initial $\mathrm{pH}$ (3 to 8) of basal salt medium at $30{ }^{\circ} \mathrm{C}$. A separate set of batch experiments was performed to investigate the effect of whey and wheat starch hydrolysate. For this, $2 \%(\mathrm{v} / \mathrm{v})$ of wheat starch hydrolysate separately and along with $10 \%$ $(\mathrm{v} / \mathrm{v})$ whey was mixed in basal salt media, which was further used for impregnation of pea peel solid bed. All the pea peel bed containing production flasks inoculated with culture solution to study the effect of $\mathrm{pH}$, whey, and wheat starch hydrolysates were placed in an incubator at $30^{\circ} \mathrm{C}$ for 6 days.

\section{Estimation of Holocellulose Content in Pea Peel Waste}

This method was used to determine the total carbohydrate contents of non-wood materials. Holocellulose in non-wood raw materials was estimated by the TM1-A-9 test 
method mentioned in the laboratory manual of Central Pulp and Paper Research Institute (CPPRI) Saharanpur, U.P., India. $5 \mathrm{~g}$ of ground sample on O.D. basis (passed through mesh size 40) was taken in a $250 \mathrm{~mL}$ conical flask, wetted thoroughly with $10 \mathrm{~mL}$ of distilled water, followed by the addition of $1.5 \mathrm{~g}$ of sodium chlorite along with $0.5 \mathrm{~mL}$ of acetic acid. The mixture was incubated in a conical flask for one hour at $70{ }^{\circ} \mathrm{C}$ in a water bath. After cooling the conical flask, the supernatant was transferred to a tared crucible $\left(\mathrm{W}_{1}\right)$. Treatment of water, sodium chlorite, and acetic acid was repeated. The filtered contents of the conical flask were transferred into a tared crucible, followed by washing the residue with acetone. The solids were dried it in oven at $105{ }^{\circ} \mathrm{C}$ for two hours, and the filtering crucible was weighed with its contents $\left(\mathrm{W}_{2}\right)$.

Holocellulose percentage was evaluated by the following equation (Laboratory manual 2001):

$$
\text { Holocellulose } \%=\left(W_{2}-W_{1}\right) \times 100 / \text { O.D. weight of sample }
$$

\section{Estimation of Lignin Content in Pea Peel Waste}

Acid-insoluble lignin was estimated as per the TM1-A-7 test method mentioned in the laboratory manual of CPPRI (Laboratory manual 2001). It involves addition of 2 $\mathrm{mL} 72 \% \mathrm{H}_{2} \mathrm{SO}_{4}$ into $1 \mathrm{~g}$ of oven-dry-basis sample in a $100 \mathrm{~mL}$ beaker, followed by addition of $13 \mathrm{~mL}$ of $72 \% \mathrm{H}_{2} \mathrm{SO}_{4}$. The mixture was kept in the beaker in a water bath at $20{ }^{\circ} \mathrm{C}$ with continous stirring for 2 hours. The contents of the beaker were filtered through a tared $\mathrm{G} 2$ crucible that weighed $\left(\mathrm{W}_{1}\right)$. The residue was dried with the crucible in an oven at $105{ }^{\circ} \mathrm{C}$ overnight and weighed $\left(\mathrm{W}_{2}\right)$. The acid-insoluble lignin was assessed by the following expression:

Acid insoluble lignin \%= $\left(W_{2}-W_{1}\right) \times 100 /$ O.D weight of sample

The filtrate obtained from the G2 crucible was kept for soluble lignin estimation, which was measured spectrophotometrically at $280 \mathrm{~nm}$. Acid-insoluble lignin can be estimated through the following expression (Laboratory manual 2001):

Acid soluble lignin $\%=\{$ (Absorbance at $280 \mathrm{~nm} \times$ Dilution factor $/ 20) \times$ 100\} /1000 x O.D weight of sample

\section{Determination of Ash Content}

$5 \mathrm{~g}$ of ground OD sample (passed through mesh size 40 ) were taken in a sintered crucible and then placed inside a muffle furnance at $600{ }^{\circ} \mathrm{C}$ for two hours, followed by cooling in a desicator. Ash content was calculated by the following expression:

Ash $\%=W_{2}$ (weight of ash with crucible) $-W_{1}$ (weight of only crucible) $\mathrm{x}$ 100/OD weight of sample 


\section{Measurement of Moisture Content}

The moisture content of the medium was estimated by drying $5 \mathrm{~g}$ of the wet sample to a constant weight at $105^{\circ} \mathrm{C}$, and the dry weight was recorded.

\section{XRD Analysis}

XRD was used to determine the crystalline content of raw materials. XRD diffraction of samples was recorded on a Bruker AXS D8 Advance diffractometer, having copper target with a scanning rate of $2 \%$ min operating at $40 \mathrm{KV}$ and $30 \mathrm{~mA}$. The sample was mounted horizontally while the Geiger counter moved in a vertical arc. The samples were scanned in the range from $0^{\circ}$ to $70^{\circ}$ angle.

\section{FTIR Spectral Analysis}

Fourier transform infrared (FTIR) spectroscopy is a promising tool for the rapid, noninvasive, and multiparameter analysis of samples. The method was used for identifying the constituents of lignocellulosic samples. FTIR spectroscopy was performed by using a Nicolet 6000 spectrophotometer. Samples were oven-dried at $105{ }^{\circ} \mathrm{C}$ for $4 \mathrm{~h}$, mixed with $\mathrm{KBr}$ in the ratio of 1:200 $\mathrm{mg}$ (raw material: $\mathrm{KBr}$ ), and pressed under vaccum to form the pellets. Transmittence was measured over a range from 4000 to $500 \mathrm{~cm}^{-1}$.

\section{Lactose Analysis}

Lactose content of the cheese whey was estimated by a spectrophotometric method (Nickerson et al. 1976). The absorbance of the sample was evaluated at $540 \mathrm{~nm}$.

\section{Pretreatment of Starch}

Acid pretreatment of starch was carried out by using $2 \%, 5 \%$, and $10 \% \mathrm{HCl}(\mathrm{v} / \mathrm{v})$ solution. $10 \mathrm{~g}$ of wheat starch powdered biomass was taken, and $40 \mathrm{~mL}$ of diluted $\mathrm{HCl}$ solution with specific strength was added to maintain the slurry of about $25 \%$. Afterwards wheat starch slurry was subjected to steam treatment under a pressure of 15 psi at $121{ }^{\circ} \mathrm{C}$ for $1 \mathrm{hr}$ and $3 \mathrm{hr}$ time duration. The treated starch slurry was used in the production medium as pure hydrolyzates.

\section{Inoculum Development}

Trichoderma reesei NCIM 1186 strain was procured from National Chemical Laboratory (NCL), Pune, India. For inoculum development an experiment was performed in $250 \mathrm{~mL}$ Erlenmeyer flasks containing $100 \mathrm{~mL}$ of potato dextrose broth (PDB) medium (In $\mathrm{g} / \mathrm{L}$ peeled potato, 200; dextrose, 20; and yeast extract, 0.1), in which 5 loopfull cultures of mycelial conidia were added and shaken at $180 \mathrm{rpm}$ at $30{ }^{\circ} \mathrm{C}$ in an incubator shaker for 3 to 4 days (Domingues et al. 2004). A definite volume of prepared cultures in PD broth suspension (having $0.56 \mathrm{~g} / \mathrm{L}$ cell dry weight) were used as inoculum for further production studies.

\section{Dry Weight Determination}

$5.0 \mathrm{~mL}$ of culture solution was taken from potato dextrose broth medium. It was then filtered on a dried and preweighed Whatman filter paper No 1. Further the solids collected were washed thoroughly with cold distilled water and with $5.0 \mathrm{~mL}$ of $0.9 \%$ 
sterile saline solution. The filter with mycelium was then dried for $24 \mathrm{~h}$ at $105^{\circ} \mathrm{C}$ until attainment of constant weight and weighed. The determination of fungal growth by cell dry weight were expressed as the mean of three independent readings.

\section{Preparation of Production Media}

Three types of production medium were used for production studies. (I) Normal basal salt media was used for production studies having the following constituents $(\mathrm{g} / \mathrm{L})$ : urea, 0.3; $\left(\mathrm{NH}_{4}\right)_{2} \mathrm{SO}_{4}, 1.4 ; \mathrm{KH}_{2} \mathrm{PO}_{4}, 2.0 ; \mathrm{MgSO}_{4} .7 \mathrm{H}_{2} \mathrm{O}, 0.3$; peptone, 1.0; Tween 80, 0.2; $\mathrm{FeSO}_{4} .7 \mathrm{H}_{2} \mathrm{O}, \quad 0.005 ; \mathrm{MnSO}_{4} .7 \mathrm{H}_{2} \mathrm{O}, 0.0016 ; \mathrm{ZnSO}_{4} .7 \mathrm{H}_{2} \mathrm{O} ; 0.0014 ; \mathrm{CaCl}_{2} .2 \mathrm{H}_{2} \mathrm{O}$; $\mathrm{CoCl}_{2} \cdot 6 \mathrm{H}_{2} \mathrm{O}, 0.02$. (II) In whey containing production media, $10 \%(\mathrm{v} / \mathrm{v})$ whey were incorporated in the earlier described production media. (III) In whey + starch hydrolysates containing production media $10 \%(\mathrm{v} / \mathrm{v})$ whey as well as $2 \%(\mathrm{v} / \mathrm{v})$ wheat starch hydrolysate were incorporated in the earlier described production media.

\section{Preparation of Raw Material}

Pea peel waste was dried then ground and sieved with a mesh screen. Ground raw material of $850 \mu \mathrm{m}$ particle size was used as a solid substrate for cellulase production studies.

\section{Solid State Fermentation Process}

A separate set of fermentation experiments was carried out in $250 \mathrm{~mL}$ Erlenmeyer flasks containing sieved raw material as the carbon source, which was impregnated with the earlier discussed production medium. Raw material soaked with normal as well as modified basal salt medium was autoclaved, cooled, and then inoculated with a specific volume having $(0.56 \mathrm{~g} / \mathrm{L}$ cell dry weight) of PD broth culture solution of $T$. reesei. The autoclaved and inoculated flasks were placed in an incubator at $30{ }^{\circ} \mathrm{C}$ for 6 days.

\section{Extraction and Assay of Enzyme}

Distilled water was added to the fermented samples (in a 1:5 proportion in Erlenmeyer flasks, and the extraction was done after shaking in shaker at $150 \mathrm{rpm}$ for $1 \mathrm{~h}$. The sample was then filtered and the extract obtained was centrifuged at $6000 \mathrm{rpm}$. The resulting supernatant was stored and used as an enzyme source. All extractions were conducted in duplicate.

\section{Total Cellulase Activity (Filter Paper Activity)}

Filter paper activity (FPase) was determined by the method recommended by Ghose (1987).

\section{Scanning Electron Microscopy (SEM)}

Scanning electron microscopy was used to investigate the surface properties of treated and untreated raw materials. In this study the samples were coated with a gold film. The samples were then examined using scanning electron microscope model LEO$435 \mathrm{VP}$. 


\section{RESULTS AND DISCUSSION}

\section{Characterization of Pea Peel Waste}

Proximate analysis of pea peel waste

To determine the suitability and effectiveness of pea peel waste for cellulase production, separate set of experiments and analysis have been performed. To resolve the major constituent of pea peel waste, proximate analyses were executed.

Table 1 describes the major constituents as holocellulose and lignin present in the dried and grounded peapeel waste. The rest of the valuable constituents present in this raw material may be pectins and antioxidants. The crystallinity of cellulose, accessible surface area, protection of cellulose by lignin, the heterogenous character of the biomass particles, and cellulose sheathing by the hemicellulose, all contribute to the recalcitrance of lignocellulosic biomass to hydrolysis (Mielenz 2001).

Table 1. Content of Major Constituents of Ground, Sieved, and Oven-dried Pea Peel Waste

\begin{tabular}{|c|c|}
\hline Constituents & \% composition \\
\hline Holocellulose & $61.35 \pm 4.96$ \\
\hline Lignin & $22.12 \pm 3.18$ \\
\hline Ash & $4.80 \pm 1.76$ \\
\hline Moisture & $3.53 \pm 0.67$ \\
\hline
\end{tabular}

Data are reported as mean \pm standard deviation based on the repeated trails.

XRD pattern of pea peel waste

The XRD pattern of pea peel waste showed a greater number of peaks with modest peak height, as can be observed form Fig 1. This XRD pattern revealed random crystallinity of raw materials, which might create some impediment to easy cellulose availability for microbial hydrolysis.

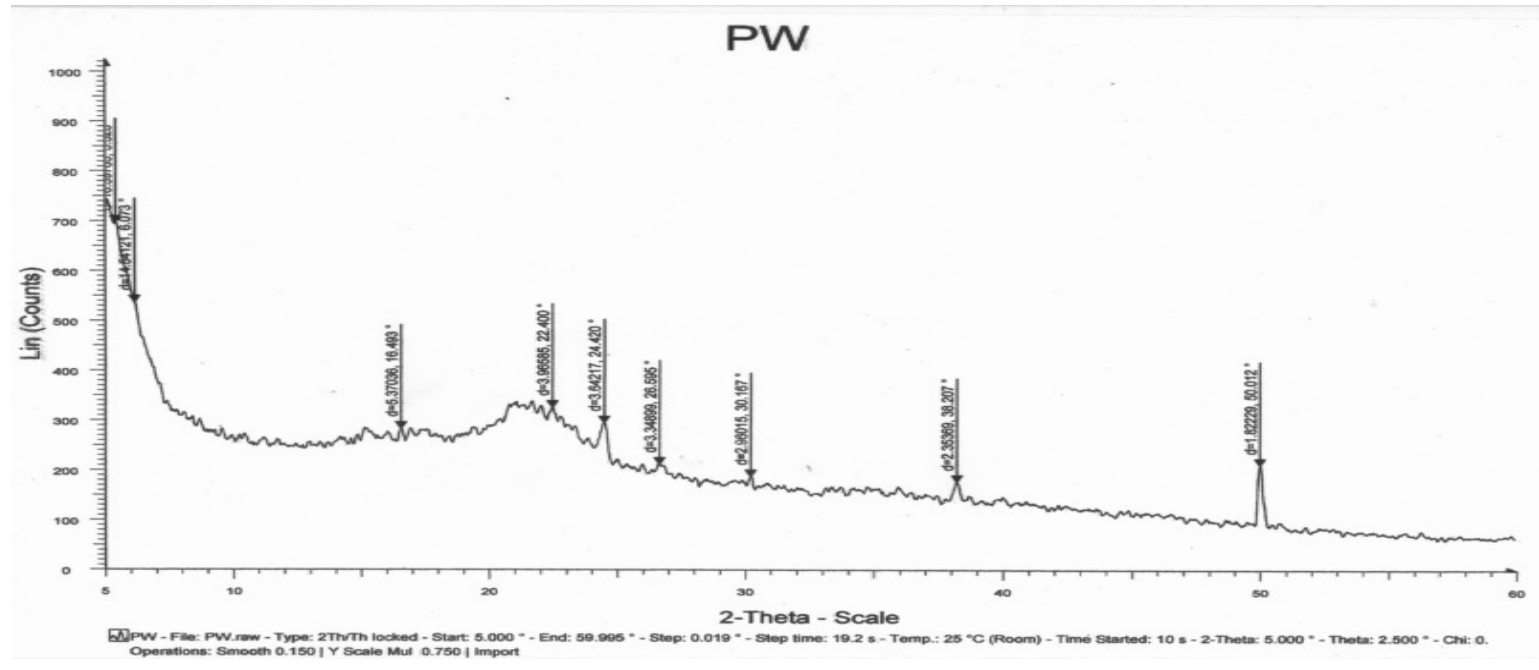

Fig 1. XRD pattern of pea peel waste 


\section{FT-IR spectra of pea peel waste}

FTIR spectroscopy was used for identifying the constituents of lignocellulosic structure. The lignocellulosic composition of peawaste could be identified from the peak presence between $3436 \mathrm{~cm}^{-1}$ and $895 \mathrm{~cm}^{-1}$. FTIR spectra of pea peel waste showed several peaks $\left(3436 \mathrm{~cm}^{-1}, 2921 \mathrm{~cm}^{-1}, 1640 \mathrm{~cm}^{-1}, 1421 \mathrm{~cm}^{-1}, 1326 \mathrm{~cm}^{-1}, 1252 \mathrm{~cm}^{-1}, 1152\right.$ $\mathrm{cm}^{-1}, 1069 \mathrm{~cm}^{-1}$, and $895 \mathrm{~cm}^{-1}$ ) in this region, as shown in Fig 2. The spectra of pea peel waste show intense band at $3436 \mathrm{~cm}^{-1}$ related to the $-\mathrm{OH}$ stretching vibration of either hydrogen bonded hydroxyls or hydroxyl groups in the phenolic (guaiacyl or syringyl monomer unit of lignin) and aliphatic compounds (Ibrahim et al. 2010a).Vibrational spectra at $2921 \mathrm{~cm}^{-1}$ may be assigned to the $(\mathrm{C}-\mathrm{H})$ stretch band of methyl groups in lignin (Ibrahim et al. 2010b). The spectral band at $2843 \mathrm{~cm}^{-1}$ may be due to the methoxyl groups $\left(-\mathrm{OCH}_{3}\right)$ that are present in the lignin (Guo et al. 2009).

The peak in the spectrum near $1640 \mathrm{~cm}^{-1}$ is assigned primarily due to the $\mathrm{C}=\mathrm{O}$ stretching vibration of alpha-keto carbonyl for cellulose (Ibrahim et al. 2010b; Guo et al. 2009). The spectral band at $1421 \mathrm{~cm}^{-1}$ may be due to $\mathrm{C}-\mathrm{H}$ deformation vibrations of $\mathrm{CH}_{2}$. The band near $1326 \mathrm{~cm}^{-1}$ may be ascribed to syringyl ring breaking C-O stretching of phenol, whereas the band at $1252 \mathrm{~cm}^{-1}$ may possibly be due to $\mathrm{C}-\mathrm{O}$ stretching in the acetyl and phenolic groups (Tserki et al. 2005; Kumar et al. 2010).

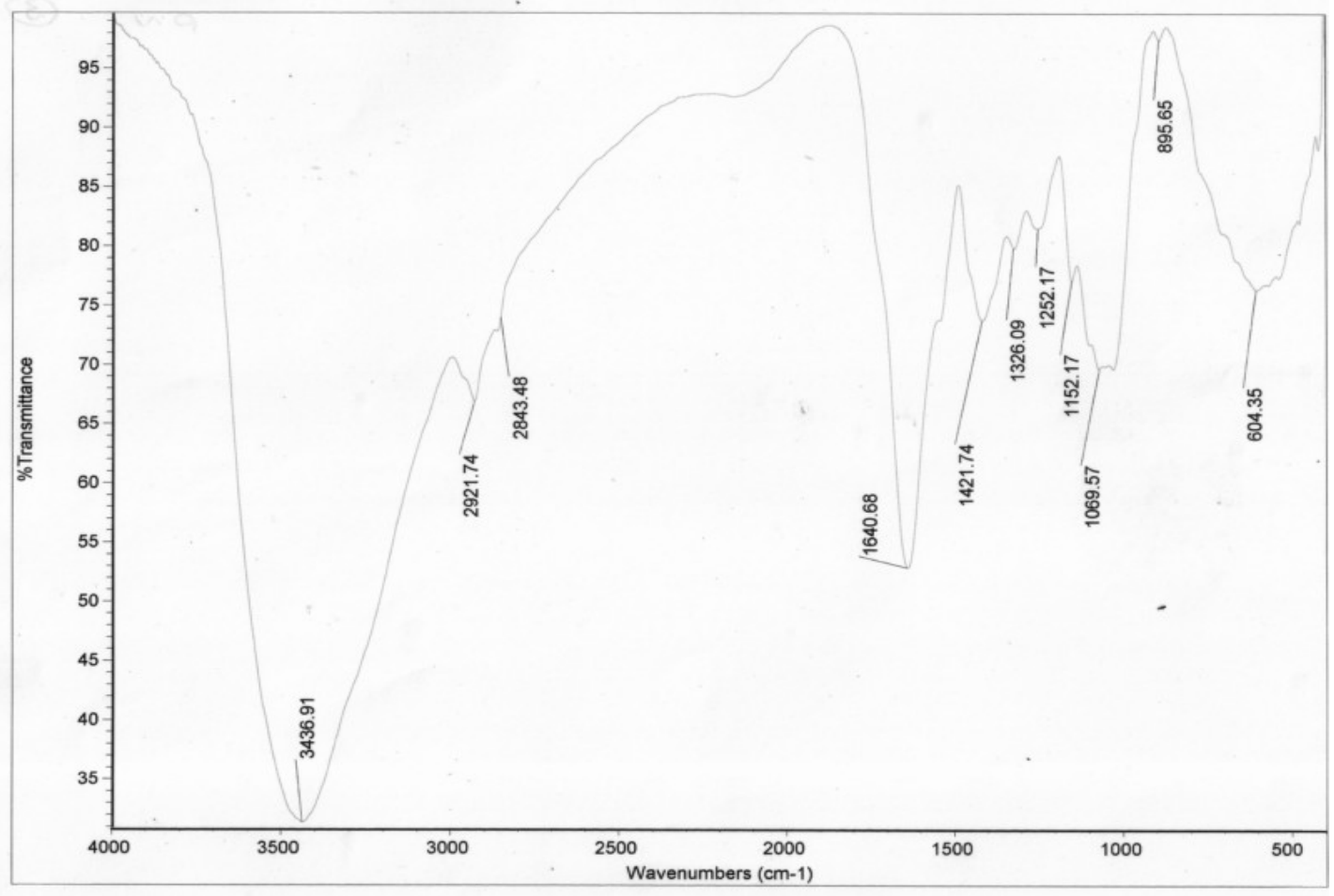

Fig 2. FTIR spectral diagram of untreated dried, grounded pea peel waste

The spectral band near $1152 \mathrm{~cm}^{-1}$ might be due to presence of $\mathrm{C}-\mathrm{O}-\mathrm{C}$ antisymmetric bridge stretching vibration in cellulose and hemicelluloses (arabinoxylan) structure (Tserki et al. 2005). The absorption band at $1069 \mathrm{~cm}^{-1}$ may be due to $\mathrm{C}-\mathrm{OH}$ streching vibration of the cellulose backbone (Spiance et al. 2009). The presence of the vibrational peak at $895 \mathrm{~cm}^{-1}$ may be assigned to $\mathrm{C}-\mathrm{H}$ deformation of cellulose as well as 
$\beta$-glucosidic linkage between sugars (Tserki et al.2005; Yang et al,2009). The FTIR spectral diagram showed peaks at $3436 \mathrm{~cm}^{-1}, 2921 \mathrm{~cm}^{-1}, 1326 \mathrm{~cm}^{-1}$, and $1252 \mathrm{~cm}^{-1}$, suggesting the presence of lignin and phenolic compounds in reasonable amounts, which creates some hindrance to the uptake of cellulose by the fungal system. FTIR spectra of pea peel waste also showed the presence of a sizeable amount of cellulose required for efficient production of cellulases.

\section{Utilization of Pea Peel Waste in Cellulase Production}

Separate sets of batch experiments were performed for the cellulase production studies by $T$. reesei. It was observed that Trichoderma grew well when pea peel based solid bed was used as the carbon source, as shown by Fig. $3 \mathrm{~b}$ and $3 \mathrm{c}$, which proves that $T$. reesei has the ability to grow and produce cellulases on pea peel waste solid support. During thermal treatment in autoclaving a blanching process occurred, which disrupted the cell membrane, cell walls, and hydrolysed bonds, making more available the cellulosic as well as antioxidant and phenolic constituents. Under these critical situations T. reesei has the ability to grow well, as observed from Figs. $3 \mathrm{~b}$ and $3 \mathrm{c}$. As literature suggested, T. reesei have the tolerance to grow in the phenolic environment up to a certain level (Selvakumar et al. 2007).

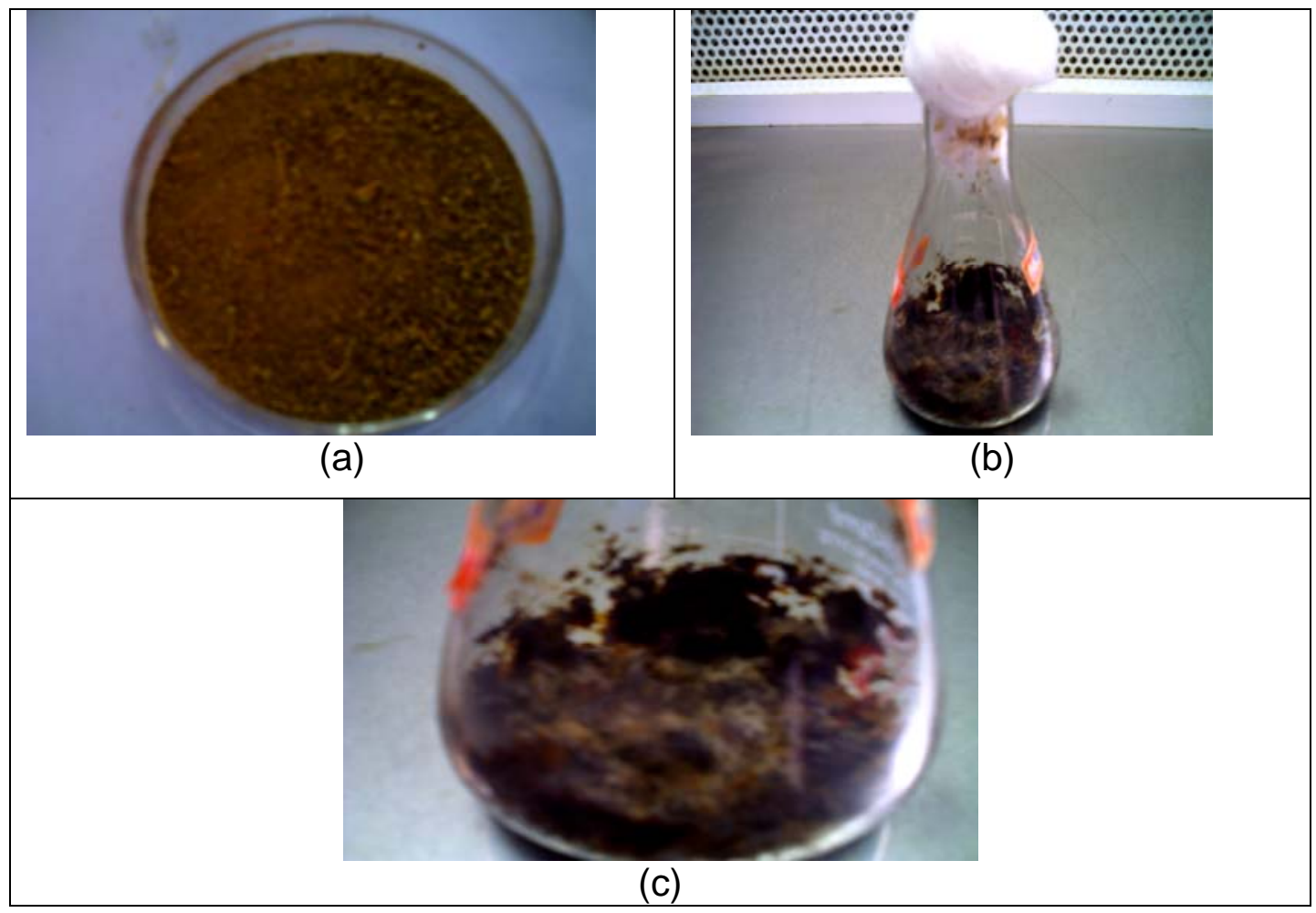

Fig 3. Ground and sieved raw pea peel waste (3a), Growth of Trichoderma reesei on pea peel waste based solid bed at $30^{\circ} \mathrm{C}$ and $\mathrm{pH} 5.0(3 \mathrm{~b}, 3 \mathrm{c})$

To study the magnified view of novel raw material as well as fungal treatment on this, scanning electron microscopy of the desired samples was carried out. 


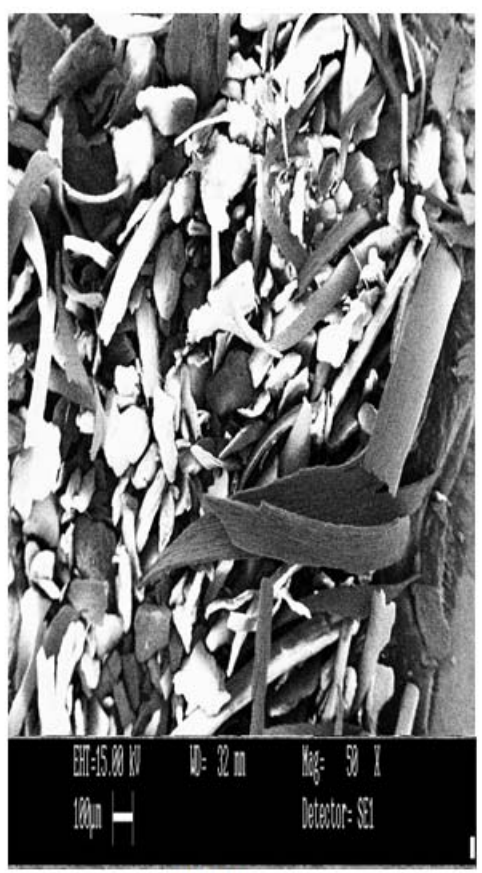

2(a)

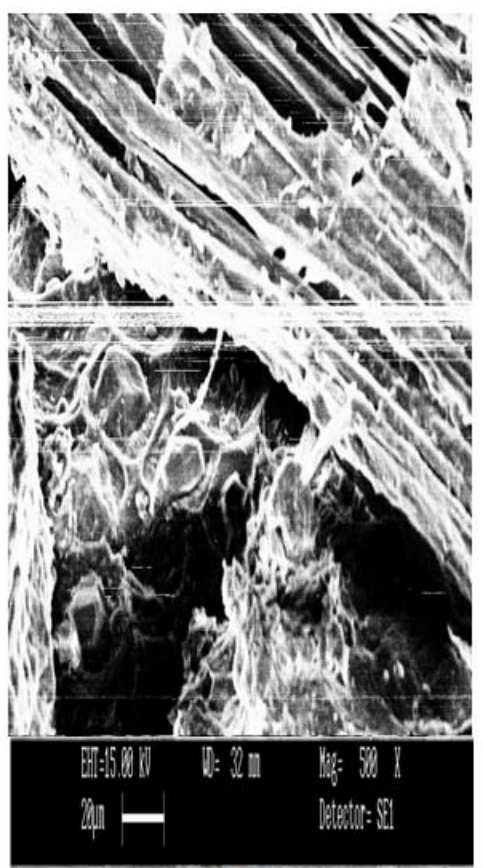

2(b)

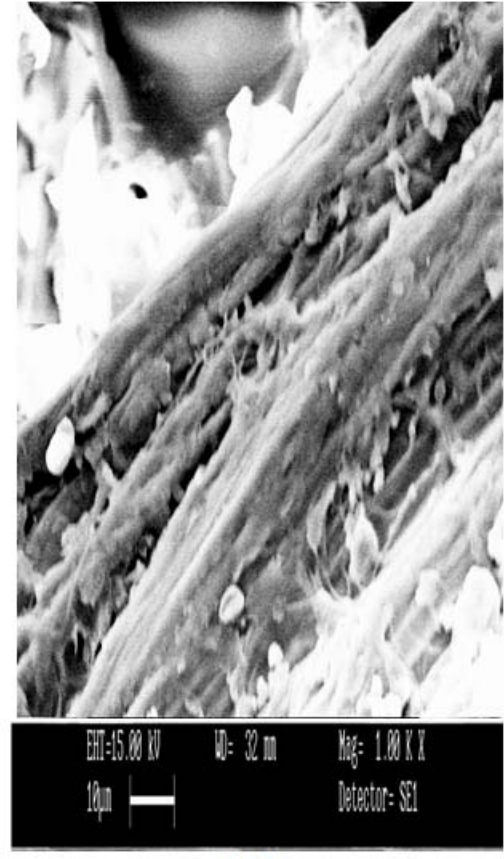

2(c)

Fig 4. SEM micrograph of untreated pea peel waste under $50 \times$ magnification(4a), Trichoderma reesei treated pea peel waste solid bed under 500X magnification(4b),1000X magnification (4c)

As show in the SEM micrograph (Fig. 4a), the untreated pea peel waste had both rough and smooth types of surfaces with shapeless pointed morphology. Figures (4b and 4c) give magnified views of $T$. reesei-treated pea peel waste. It was observed that the surface of raw material became ruptured due to the fungal action, as they are utilizing raw material as a carbon source.

Table 2. Cellulase Activity by Trichoderma reesei on Pea Peel Solid Bed, used as Raw Material at Different Temperatures and $\mathrm{pH}$

\begin{tabular}{|c|c|c|c|}
\hline Raw material used & Parameters & & FPase(IU/mL) \\
\hline \multirow{11}{*}{ Pea peel waste } & \multirow{5}{*}{ Temp $\left({ }^{\circ} \mathrm{C}\right)$} & 25 & $1.65 \pm 0.15$ \\
\hline & & 27 & $2.13 \pm 0.18$ \\
\hline & & 30 & $2.86 \pm 0.10$ \\
\hline & & 32 & $2.35 \pm 0.16$ \\
\hline & & 35 & $1.97 \pm 0.20$ \\
\hline & \multirow{6}{*}{$\mathrm{pH}$} & 3.0 & $1.89 \pm 0.12$ \\
\hline & & 4.0 & $2.41 \pm 0.21$ \\
\hline & & 5.0 & $2.86 \pm 0.10$ \\
\hline & & 6.0 & $2.07 \pm 0.17$ \\
\hline & & 7.0 & $1.71 \pm 0.15$ \\
\hline & & 8.0 & $1.53 \pm 0.13$ \\
\hline
\end{tabular}

Data are reported as mean \pm standard deviation based on the repeated trials. 
Cellulase production was compared under various temperature and $\mathrm{pH}$ conditions with $T$. reesei treatment. As shown in Table 2, temperature above or below $30{ }^{\circ} \mathrm{C}$ was somewhat unfavorable for cellulase production by T. reesei, which might be due to their physiological nature and protein synthesis capability. At $35{ }^{\circ} \mathrm{C}$ temperature, significant decrement in the enzyme activity has been observed, which might be due to the fact that at higher temperature enzyme biosynthesis decreases due to thermal deactivation, while at lower temperature $\left(25^{\circ} \mathrm{C}\right)$ the transport of nutrients in the cells is hindered, and due to this the microbial enzyme production capability is decreased (Pirt 1976). Maximum cellulase $(2.86 \pm 0.10 \mathrm{IU} / \mathrm{mL})$ activity was exhibited by $T$. reesei at $30{ }^{\circ} \mathrm{C}$.

On the other hand, $\mathrm{pH} 5.0$ was found to be highly favorable for cellulase production. Cellulase activity was significantly decreased in higher or lower pH-based production media. This suggests that a highly acidic or alkaline condition becomes unfavorable for microbial growth and for the cellulase production system. An acidic $\mathrm{pH}$ favored cellulase production, while this was significantly decreased towards much acidic as well as neutral and slight alkaline $\mathrm{pH}$, as observed from Table 2. The most effective temperature and $\mathrm{pH}$ for T. reesei growth and production system was $30{ }^{\circ} \mathrm{C}$ and 5.0.

To investigate the role of starch hydrolysates in cellulase production, a separate set of experiments was performed. Pretreatment of starch was performed by taking 2 and $5 \% \mathrm{HCl}$ with varying pretreatment time.

Table 3. Growth of Trichoderma reesei on Acid Pretreated Wheat Starch Hydrolysates at $30{ }^{\circ} \mathrm{C}$ and $\mathrm{pH}$ 5.0.(Mandal et al. 2010)

\begin{tabular}{|c|c|c|c|c|}
\hline $\begin{array}{c}\text { Starch } \\
\text { type }\end{array}$ & $\begin{array}{c}\text { Acid treatment } \\
\text { dosages }\end{array}$ & $\begin{array}{c}\text { Pretreatment } \\
\text { time (hr) }\end{array}$ & Temp ${ }^{\circ} \mathrm{C}$ & $\begin{array}{c}\text { Trichoderma reesei growth in } \\
\text { pure starch hydrolysate-based } \\
\text { medium }\end{array}$ \\
\hline \multirow{3}{*}{ Wheat } & Untreated & - & - & No growth \\
\cline { 2 - 3 } & \multirow{2}{*}{$2 \% \mathrm{HCl}$} & 1 & \multirow{2}{*}{121} & Good growth \\
\cline { 2 - 3 } & \multirow{2}{*}{$5 \% \mathrm{HCl}$} & 3 & & Very light growth \\
\cline { 2 - 3 } & & 1 & & Very light growth \\
\cline { 2 - 3 } & & 3 & & Not suitable \\
\hline
\end{tabular}

From the above experimental observation we have observed that wheat starch was converted into soluble form after hydrolysis. $2 \% \mathrm{HCl}$ treatment was more favorable than $5 \%$ for starch hydrolysis. Pretreatment of wheat starch with $2 \% \mathrm{HCl}$ having pretreatment time of $1 \mathrm{~h}$ was found most suitable for the Trichoderma growth in comparison to higher acid dosages with higher pretreatment time.

At higher acid dosages with higher pretreatment time, extreme hydrolysis occurred therefore essential components present in the starch were destroyed or burnt out due to higher acidity with prolonged pretreatment time as observed from Table 3.

It has been stated from Table 3 that inclusion of wheat starch hydrolysate in basal salt media used for production study provides significant results. Under this situation, increment in the FPase activity $(3.02 \pm 0.03 \mathrm{IU} / \mathrm{mL})$ was observed. In all the media combinations having hydrolyzates, growth and cellulase induction both took place, presumably due to the release of some dimeric sugars in the hydrolyzates, which induces cellulase production. The inducing ability of the acid-hydrolyzed starch may be attributed 
to the reversion product of glucose, by increasing the acid strength, resulting in more reversion products of glucose in the hydrolyzates, which are responsible for the induction capability of the starch. But when the starch is overhydrolyzed, other byproducts may be generated, which might have served as inhibitors for cellulase production (Chen and Wayman 1992).

Table 4. Cellulase Activity Produced by Trichoderma reesei on Normal Basal Salt as well as Modified Basal Salt Media Incorporated on Pea Peel Waste based Solid Bed at $30{ }^{\circ} \mathrm{C}$ and $\mathrm{pH} 5.0$

\begin{tabular}{|c|c|c|}
\hline Raw material used & Basal salt media used & FPase $(\mathrm{IU} / \mathrm{mL})$ \\
\hline \multirow{5}{*}{ Pea peel waste } & Normal basal salt media & $2.86 \pm 0.10$ \\
\cline { 2 - 3 } & $\begin{array}{c}\text { Basal salt media incorporated with } \\
2 \%(\mathrm{v} / \mathrm{v}) \text { wheat starch hydrolysates }\end{array}$ & $3.02 \pm 0.03$ \\
\cline { 2 - 3 } & $\begin{array}{c}\text { BSM incorporated with } 10 \%(\mathrm{v} / \mathrm{v}) \\
\text { whey }+2 \%(\mathrm{v} / \mathrm{v}) \text { wheat starch } \\
\text { hydrolysates }\end{array}$ & $3.29 \pm 0.08$ \\
\hline
\end{tabular}

Data are reported as mean \pm standard deviation based on the repeated trails.

In the previous study it was found that starch itself was a poor inducer for cellulase production, but it was rendered highly effective by acid hydrolysis. This was because of the acid hydrolysis of starch resulted in the formation of reversion products, such as sophrose, a disaccharide, which has been considered to be to the real inducers for the cellulase biosynthesis (Sternberg and Mandels 1979).

In the other set of experiments, dairy industry whey was incorporated in the basal salt media for the production study on pea peel substrate. FPase activity $(3.29 \pm 0.08 \mathrm{IU} / \mathrm{mL})$ was further enhanced by incorporation of $10 \%(\mathrm{v} / \mathrm{v})$ whey in the earlier starch hydrolysate supplemented basal salt medium, as shown in Table 4 . This might be due to the presence of lactose in the whey, which itself act as inducer for cellulase production in $T$. reesei. Lactose is a low commercial cost disaccharides and it is generated in large amounts during the cheese and other dairy products manufacturing, act as the source of carbon as well as inducer for the cellulase production by fermentation (Sehnem et al. 2006).

On the other hand Pea peel waste was found to be a suitable raw material for cellulase production by Trichoderma reesei under solid state fermentation, which might be due to the presence of cellulose, which significantly induces the cellulase production.

\section{CONCLUSIONS}

Waste utilization is an alternative approach for waste management. Keeping in view the importance of cellulases in various process industries, effective and economical production of these enzyme is of utmost importance.

Cellulase production by utilizing cheap lignocellulosic waste such as pea peel waste would be a novel approach, which can allow cost-effective cellulase production. Consumption of dairy industry waste (whey) as well as wheat starch hydrolysate in the cellulase production could meets in the cost reduction strategy. Hence the utilization of 
all waste material, not only provides a cost effective and environmental friendly technology, but is also helpful up to some extent in the solid as well as liquid waste bioresource management. Application of recombinant cultures or application of phenol degrading microbes along with cellulase producing cultures should be investigated in the future research for the effective and proper utilization of phenol/lignin enriched lignocellulosic wastes.

\section{ACKNOWLEDGEMENTS}

Authors gratefully acknowledge the support and facilities provided by Indian Institute of Technology, Roorkee, India for scanning electron microscopic (SEM), XRD, and FTIR facilities. They also acknowledged the Ministry of human resource and development, India for providing fellowship to carry out present research work.

\section{REFRENCES CITED}

Ahmad G., Mudasir., Kudesia, R., Shika., and Srivastava, M. K. (2010). "Evaluation of genetic diversity in pea (Pisum sativum L) using RAPD analysis," Genetic Engg. Biotechnol . J. 16, 1-5.

Anekar, S., and Rao, C. R. (2009). "Ultra filtration - Tool to recover valuable constituent from dairy waste water," J. Appl. Sci. Environ. Sanitation 4(2), 125-132.

Anon 2011, International starch institute, Denmark, Technical memorandum on wheat starch,http://www.starch.dk/isi/starch/tm33wheat.asp.

Atkins, C. A., Kuo, J., Pate, J. S., Flinn, A. M., and Steele, T. W. (1977). "Distribution of carbon dioxide-fixing enzymes in relation to pod structure," Plant Physiol. 60, 779786.

Chen, S., and Wayman, M. (1992). "Novel inducers derived from starch for cellulase production by Trichoderma reesei," Process Biochem. 27, 327-334.

Chen, S., and Wayman, M. (1993). "Use of sorbose to enhance cellobiose activity in a Trichoderma reesei cellulase system produced on wheat hydrolysates," Biotechnol. Techniques 7, 345-350.

Choi, W. S., and Han, K. J. H. (2001). "Physical and mechanical properties of peaprotein-based edible films," J. Food Sci. 66, 319-322.

Domingues, F. C., Queiroz, J. A., Cabral, J. M. S., and Fonseca, L. P. (2004). "The influence of culture conditions on mycelial structure and cellulase production by Trichodermma reesei RUT C-30," Enzyme Microbial Technol. 26, 394-401.

Ghose, T. K. (1987). "Measurement of cellulase activities," Pure Appl. Chem. 59(2), 257268.

Gunaseelana, V. N. (2007). "Regression models of ultimate methane yields of fruits and vegetable solid wastes, sorghum and napier grass on chemical composition," Bioresource Technol. 98(6), 1270-1277. 
Guo, G. L., Hsu, D. C., Chen,Wen H.,Chen,Wei H., and Hwong, W. S. (2009). Charecterisation of enzymatic saccharification for acid pretreated lignocellulosic materials with different lignin composition," Enzyme Microbial Technol. 45(2), 8087.

Ibrahim, M. N. M., Ahmed-Haras, M. R., Sipaut, C. S., Aboul-Encin, H. Y., and Mohamed, A. A. (2010a). "Preparation and characterization of a newly water soluble lignin graft copolymer from oil palm lignocellulosic waste," Carbohydrate Polymers 80(4), 1102-1110.

Ibrahim, M. M., Dufresne, A., El-Zawawy, W. K., and Agblevor, F. A. (2010b). "Banana fibers and microfibrils as lignocellulosic reinforcements in polymer composites," Carbohydrates Polymers 81, 811-819.

Jecu, L. (2000). "Solid state fermentation of agricultural wastes for endoglucanase production," Indust. Crops Prod. 11, 1-5.

Kumar, S., Negi, Y. S., and Upadhyaya, J. S. (2010). "Studies on characterization of corn cob based nanoparticles," Adv. Mat. Lett. 1(3), 246-253.

Laboratory Manual (2001). Laboratory Manual of Central Pulp and Paper Research Institute, Analysis of fibrous raw materials, proximate chemical analysis, Saharanpur, 247001(U.P.), India, "Estimation of acid insoluble lignin in wood/nonwood," TM1A7; "Estimation of acid soluble lignin in wood/nonwood," TM1A-8; "Estimation of holocellulose in wood/nonwood"; TM1-A9.

Mateos-Aparicio, I., Redondo-Cuenca, A., and Villanueva-Suarez,(2010). "Isolation and characterisation of cell wall polysachharides from legume by-products:

Okara(soymilk residue), pea pod and broad bean pod," Food Chem. 122, 339-345.

Marwaha, S. S., and Kennedy, J. F. (2007). "Whey pollution problem and potential utilization," Int. J. Food Sci. Technol. 23, 323-336.

Mielenz, J. R. (2001). "Ethanol production from biomass: Technology and commercialization status," Cur. Opinion Microbiol. (4), 324-329.

Mandal, S. K., Bansal, M. C., Kumar, V., and Verma, N. (2010). "Studies on effect of pretreated starch on Aspergillus niger system," Proceedings of International Conference on Emerging Technologies for Sustainable Environment, at Civil Engineering Department of Aligarh Muslim University (AMU) India in collaboration with La Sierra University, U.S.A. and Asia Pacific International University, Thailand. Oct 29-30, 721-723.

Nicolopouloua, D., Grigorakisa, K., Stasinib, M., Alexia, M. N., and Iliadisc, K. (2007). "Differences in chemical composition of field pea (Pisum sativum) cultivars: Effects of cultivation area and year," Food Chem.103(3), 847-852.

Nickerson, T. A., Vujicic, I. F., and Lin, A. Y. (1976). "Colorimetric estimation of lactose and its hydrolytic products," J. Dairy Sci. 59(3), 386-390.

Pirt, S. J. (1973). Principles of Cell Cultivation, Blackwell Scientific, London.

Roy, F., Boye, J. I., and Simpson, B. K. (2010). "Bioactive protein and peptides in pulse crops: Pea, chickpea and lentil," Food Res Intl. 43, 432-442.

Selvakumar, G., Saha, S., and Kundu, S. (2007). "Inhibitory activity of pine needle extracts on some agriculturally resourceful microbes," Indian J. Microbiol. 47(3), 267-270. 
Sehnem, N. T., Bitteencourt, L. R. D., Camassola, M., and Dillon, A. J. P. (2006). "Cellulase production by Penicillium echinulatum on lactose," Appl. Microbiol. Biotechnol. 72, 163-167.

Sharma, A., Hasseb, A., and Abujar, S. (2006). "Screening of field pea (Pisum sativum) selections for their reactions to root-knot nematode (Meloidogyne incognita)." $J$. Zhejiang Univ. Sci. 7(3), 209-214.

Spiance, M. A. S., Lambert, C. S., Fermoselli, K. K. G., and De Paoli, M. A. (2009). "Characterization of lignocellulosic curaua fibers," Carbohyd. Poly. 77(1), 47-53.

Sosulski, F. W., and Wu, K. K. (1988). "High-fiber breads containing field pea hulls, wheat, corn and wild oat brans," Cereal Chem.65, 186-191.

Sultana, B., and Anwar, F. (2008). "Flavonols (kaempeferol, quercetin, myricetin) contents of selected fruits, vegetables and medicinal plants," Food Chem. 108, 879-884.

Sternberg, D., and Mandels, G. R. (1979). "Induction of cellulolytic enzymes in T.reesei by sophrose," J. Bacteriol. 139, 761-769.

Tosh, S. M., and Yada, S. (2010). "Dietary fibers in pulse seeds and fractions: Characterization, functional attributes and applications," Food Research Intl. 43, 450-460.

Tserki, V., Matzinos, P., Kokkou, S., and Panayiotou, C. (2005). "Novel biodegradable composites based on treated lignocellulosic waste flour as filler. Part I, Surface chemical modification and caracterization of waste flour," Composites Part A: Appl. Sci. Manufact. 36(7), 965-974.

Venkatraman, K., and Achi, M. (2004). "To eliminate the disposal of salty whey from a dairy industry into the sewer in an environmental, social and economical way - A case study from dairy farmers, Toowoomba, Queensland, Australia," Int. J. Environ. Technol. Management 4, 365-374.

Verma, N., Kumar, V., and Bansal, M. C. (2009). "Various inducers involved in environmental viable cellulase biosynthesis," Proceedings of International Conference on Emerging Technologies in Environmental Science and Engineering, at Civil Engineering Department of Aligarh Muslim University (AMU) India in collaboration with Toledo University, U.S.A., Oct 26-28, 1690-1695.

Wen, T. N., Prasad, K. N.,Yang, B., and Ismail A. (2010). "Bioactive substance contents and antioxidant capacity of raw and blanched vegetables," Innovative Food Sci. Emerging Technol. 11, 464-469.

Yang, S., Li, J., Zheng, Z., and Meng, Z. (2009). "Lignocellulosic structural changes of Spartina alterniflora after anaerobic mono and co digestion," Intl. Biodeterioration Biodegradation 63, 569-575.

Article submitted: January 12, 2011; Peer review completed: February 13, 2011; Revised version received and accepted: March 14, 2011; Published: March 16, 2011. 